\section{Regeneration of deep intrabony periodontal defects with enamel \\ matrix derivative: A case report}

\author{
Lopes Otão $\mathrm{P}^{1}$ and Mascarenhas $\mathrm{P}^{1,2 *}$
}

\begin{abstract}
${ }^{1}$ Periodontology Department, Faculty of Dental Medicine, University of Lisbon, Portugal
${ }^{2}$ Chair of Periodontology Department, Faculty of Dental Medicine, University of Lisbon, Portugal
\end{abstract}

\section{Summary}

A clinical case of treatment of two severe intrabony defects on the aesthetic zone is reported and followed for one year.

The biomaterial of choice was enamel matrix derivative $\left(E^{2}\right.$ dogain $^{\circledR}$; Straumann $\left.{ }^{\mathrm{TM}}\right)$ alone with a preservation papilla flap and a minimally invasive surgical technique.

After surgical treatment, the patient was kept in a supportive periodontal therapy programme with 6-month interval between appointments.

In the one year after surgery appointment, clinical and radiographic changes were observed, showing periodontal health and stability.

\section{Introduction}

Periodontitis often causes intrabony defects, which are associated with deep periodontal pockets. These defects can be surrounded by one, two or three residual bony walls or even their combination [1]. Intrabony defects are associated with higher risk of periodontal disease progression and to treat them a surgical approach is often required [2]. Several studies have reported that intrabony defects can be successfully treated with a regenerative surgical approach comparatively to an open access flap surgery [3,4]. It can be also confirmed with the available scientific evidence that the periodontal regenerative treatment outcome can be maintained stable over time, particularly in patients who do not smoke and are compliant with supportive periodontal therapy [5-7].

A few biomaterials have demonstrated potential for periodontal regeneration, such as enamel matrix derivative $\left(\right.$ Emdogain $^{\circledR} ;$ Straumann $^{\mathrm{TM}}$ ), demineralized bovine bone mineral, decalcified freeze-dried bone allograft and Platelet derived factors [8].

Scientific evidence is fulfilled with data that displays the predictability of the periodontal regenerative therapy [8-11], but the morphology of periodontal defects diverges vastly between studies, at this case report we have the opportunity

\section{More Information}

*Address for Correspondence: Mascarenhas $\mathrm{P}$ Chair of Periodontology Department, Faculty of Dental Medicine, University of Lisbon, Portugal, Tel: +35121792 2600;

Email: paulomascarenhas@campus.ul.pt; pedrootao@gmail.com; pmascarenhas@iro.pt

Submitted: February 16, 2021

Approved: March 18, 2021

Published: March 19, 2021

How to cite this article: Lopes Otão P,

Mascarenhas P. Regeneration of deep intrabony periodontal defects with enamel matrix

derivative: A case report. J Oral Health Craniofac Sci. 2021; 6: 001-005.

DOI: 10.29328/journal.johcs. 1001033

DOI: orcid.org/0000-0002-9361-8103

Copyright: (c) 2021 Lopes Otão P, et al. This is an open access article distributed under the Creative Commons Attribution License, which permits unrestricted use, distribution, and reproduction in any medium, provided the original work is properly cited.

Keywords: Premaxilla osteotomy; Bilateral cleft lip and palate; Cephalometric analysis

Check for updates

OPEn ACCESS to demonstrate the outcome of the periodontal regenerative treatment with enamel matrix derivative (Emdogain ${ }^{\circledR}$; Straumann ${ }^{T M}$ ) in two rare and severe intrabony defects.

\section{Case report}

A 54-year-old man was referred to the Periodontology Department of Faculty of Dental Medicine, University of Lisbon. The patient revealed that he had been treated for almost 10 years in a private practice and had been followed by a dental hygienist for that long, and it was the dental hygienist who referred the patient for a Periodontology appointment. The reason for the referral was the grade I mobility [12] found in tooth 12 and 21.

At periodontal examination it was established that the patient had a Periodontitis Stage IV, Grade B, with no grade modifiers [13]. During endodontic examination, tooth 12 and 21 responded negatively for cold sensitivity and electric tests. Consequently root canal treatment was recommended [4].

The clinical examination included radiographic analysis which revealed the presence of radiographic images compatible with intrabony defects (Figure 1). 
As treatment plan for this clinical case, it was proposed an initial phase of periodontal non-surgical therapy which included information about the periodontal disease, etiology, progression and its relationship with the host systemic conditions, followed by oral hygiene instructions (Figure 2).

Subsequently, scaling and root planing was performed on every periodontal pockets and teeth 12 and 21 were endodontically treated during the initial phase of periodontal therapy.

6 weeks after the conclusion of periodontal non-surgical therapy, a periodontal re-evaluation was performed, showing residual deep pockets in the anterior upper sector as shown in figures 3,4 which justified further corrective treatment in teeth 12 and 21.

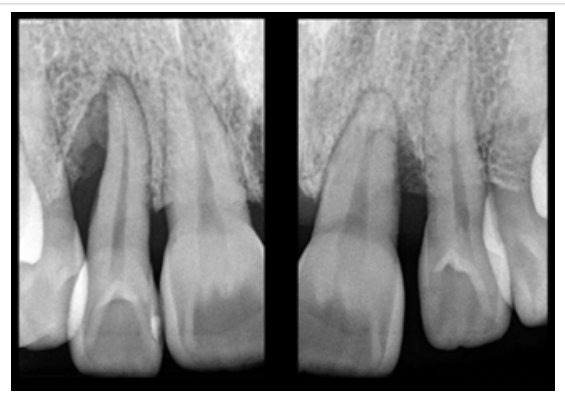

Figure 1: Radiograph showing intrabony defects at distal side of tooth 12 and 21.

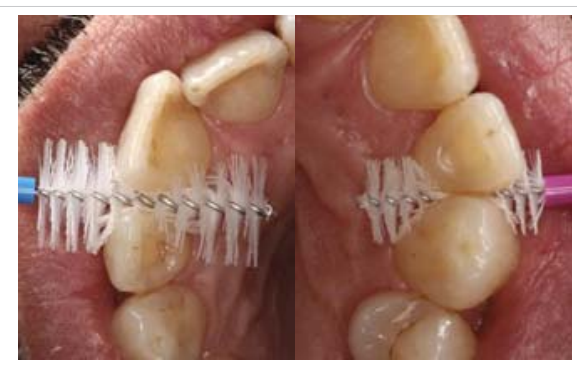

Figure 2: Oral hygiene instructions using interdental brushes.

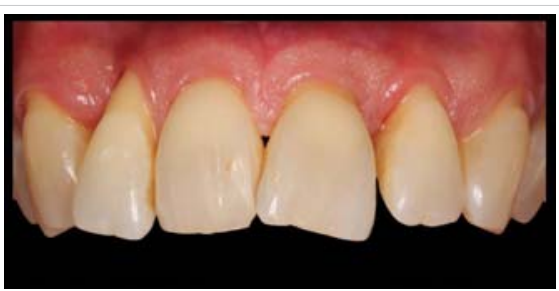

Figure 3:

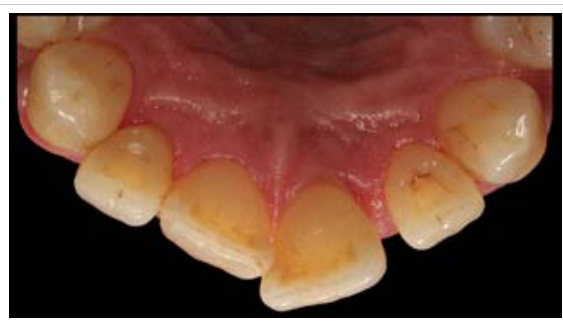

Figure 4: Clinical aspect on vestibular and palatal sides of the anterior upper sextant before surgical markings.

\begin{tabular}{|c|c|c|c|c|c|c|c|}
\hline & & 13 & 12 & 11 & 21 & 22 & 23 \\
\hline \multicolumn{2}{|c|}{ Mobility } & 0 & 1 & 0 & I & 0 & 0 \\
\hline PD & \multirow{2}{*}{ V } & $3-2-3$ & $12-4-4$ & $2-1-2$ & $3-3-10$ & $3-2-3$ & $3-2-3$ \\
\hline GM & & $1-2-2$ & $3-5-2$ & $1-1-1$ & $1-1-2$ & $3-2-3$ & $3-2-3$ \\
\hline PD & \multirow{2}{*}{$\mathrm{P}$} & $3-2-2$ & $11-4-3$ & $3-2-3$ & $7-8-10$ & $4-3-3$ & $3-2-3$ \\
\hline GM & & $0-0-0$ & $0-0-0$ & $0-0-0$ & $0-2-3$ & $0-0-0$ & $0-1-0$ \\
\hline
\end{tabular}

Considering the clinical and radiographic analysis we decided to perform a regenerative treatment with enamel matrix derivative (Emdogain ${ }^{\circledR}$; Straumann ${ }^{\mathrm{TM}}$ ) in the intrabony defects associated with teeth 12 and 21 .

\section{Surgical procedure}

For the surgical access, a conservative approach have been chosen (Figure 5), in which we made a Minimally Invasive Surgical Technique [14] related to tooth 12 and a Simplified Papilla Preservation Flap (15) for the defect associated with tooth 21.

After surgical incisions, full thickness vestibular and palatal flap were elevated (Figure 6).

All the granulation tissue was removed, and the lesion was meticulously debrided, the root surface was carefully scaled and planed (Figure 7). A defect with complex anatomy was then observed, showing 3 residual walls at apical and 2 walls at the coronal portion in tooth 12 and the same defect with circumferential involvement at the palatal portion in tooth 21 .

After the periodontal defect debridement, root surface conditioning with orthophosphoric acid at 37\% for 60 seconds was performed (Figure 8), then enamel matrix derivative (Emdogain ${ }^{\circledR}$; Straumann ${ }^{\mathrm{TM}}$ ) was applied, filling the defect from apical to coronal (Figures 9-11).

Finally, both flaps were repositioned and sutured with vertical mattress sutures and single sutures.

All post-surgery recomendations were given.

It was prescribed ibuprofen $600 \mathrm{mg}$, three times a day, for three days, then paracetamol $1 \mathrm{~g}$, for pain control. All the hygiene procedures were avoided and replaced by a $0.2 \%$ chlorhexidine mouthwash, twice a day during 1 minute for fourteen days.

All sutures were removed eight days after surgery (Figures 12-14) (Table 2).

\section{Clinical Outcome - 1 year Follow-up}

Patient was introduced into a 6 month supportive periodontal programme, remaining compliant with all the oral hygiene instructions, maintaining an optimal plaque control. After 1 year, it is possible to see clinical and 


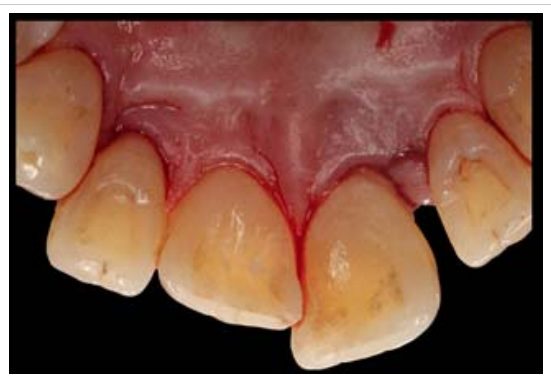

Figure 5: Surgical incisions on palatal side of the sextant of interest.

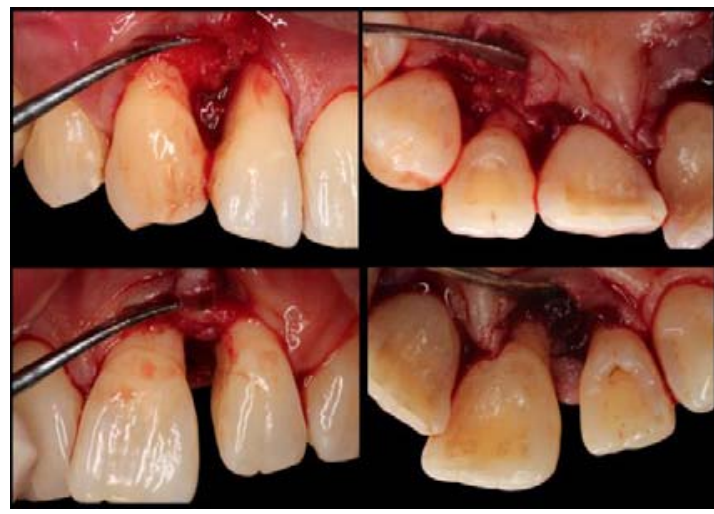

Figure 6: Full thickness flap elevation - Vestibular and Palatal view.

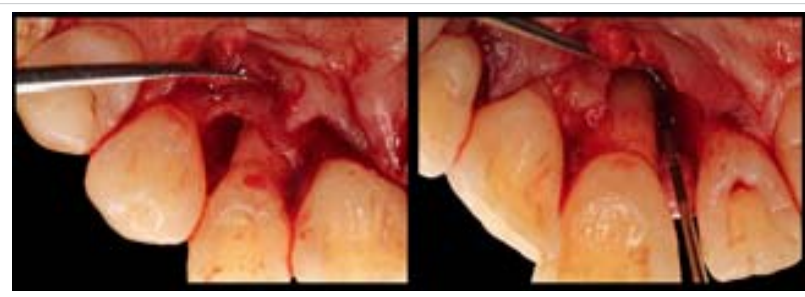

Figure 7: Palatal view of Intrabony Periodontal Defects associated with tooth 12 (left) and 21 (right).

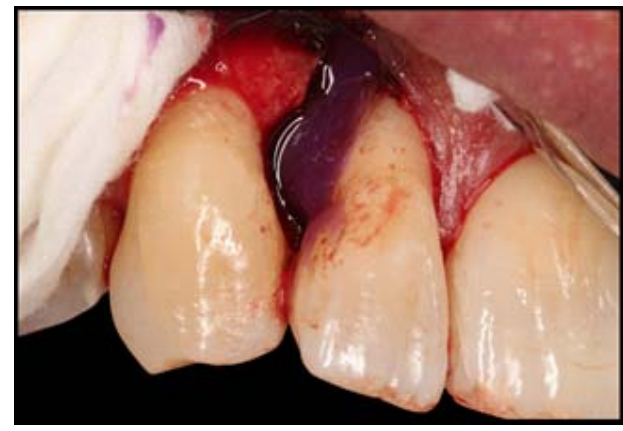

Figure 8: Root surface conditioning with orthophosphoric acid at $37 \%$ in intrabony defect associated with tooth 12 .

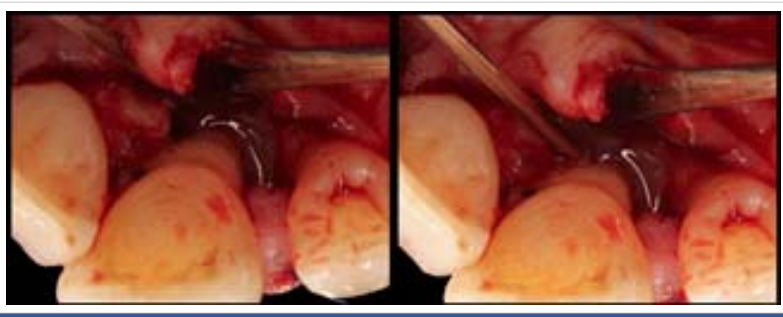

Figure 9: Defect filling with enamel matrix derivative (Emdogain ${ }^{\circledR}$; Straumann ${ }^{\mathrm{TM}}$ ) in palatal view of intrabony defect associated with tooth 21 .

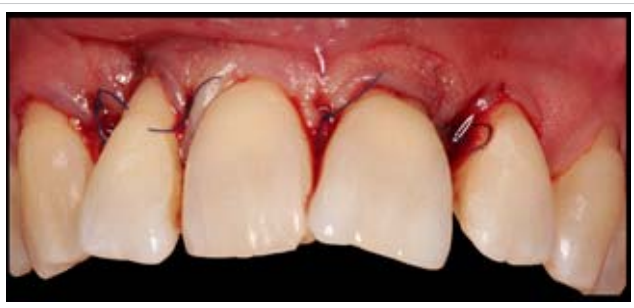

Figure 10: Final suture of vestibular aspect.

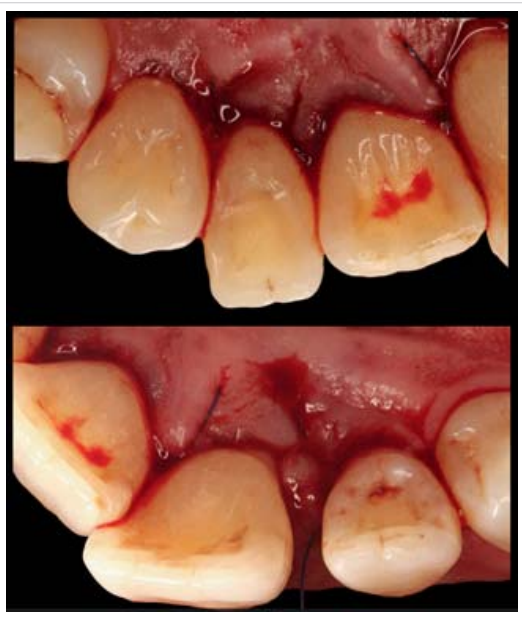

Figure 11: Final suture - Palatal Aspect.

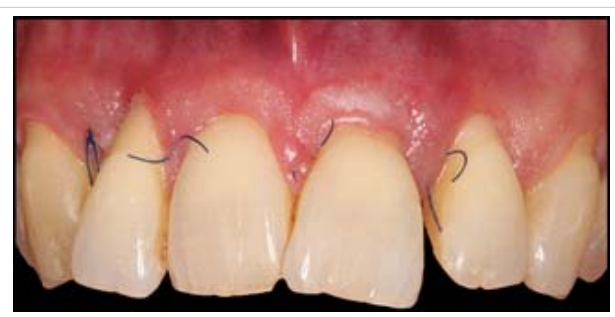

Figure 12: Cicatricial Aspect at Suture Removal - Eight days after surgery.

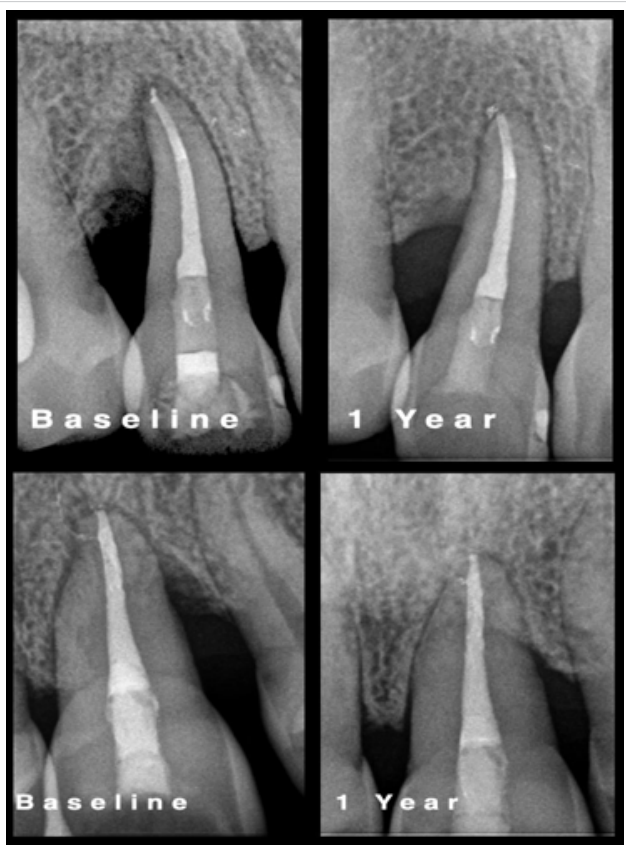

Figure 13: Radiographic Comparison at baseline and 1 Year follow-up - Upper tooth 12; lower tooth 21 


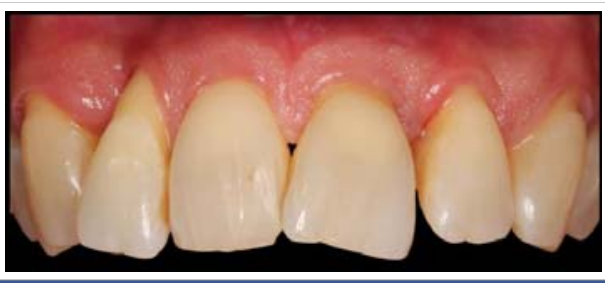

Figure 14: Clinical Situation - 1 Year Follow-up

Table 2: Periodontal probing on the aesthetic zone -1 year Follow-up.

\begin{tabular}{|c|c|c|c|c|c|c|c|}
\hline & & 13 & 12 & 11 & 21 & 22 & 23 \\
\hline \multicolumn{2}{|c|}{ Mobility } & 0 & 0 & 0 & 0 & 0 & 0 \\
\hline PD & \multirow{2}{*}{ V } & $3-2-3$ & $3-3-3$ & $3-2-3$ & 3-3-3 & $3-2-3$ & $3-2-3$ \\
\hline GM & & $1-2-2$ & $3-5-2$ & $1-1-1$ & $1-1-2$ & $3-2-3$ & $3-2-3$ \\
\hline PD & \multirow{2}{*}{$\mathrm{P}$} & $3-2-2$ & $3-3-3$ & $3-3-3$ & $3-3-3$ & $3-3-3$ & $3-2-3$ \\
\hline GM & & $0-0-0$ & $0-0-0$ & $0-0-0$ & $0-3-4$ & $0-0-0$ & $0-1-0$ \\
\hline
\end{tabular}

radiographic changes comparatively to baseline. All the visible alterations are according to the state of periodontal health [16] that should be maintained with appropriate periodontal supportive care.

\section{Discussion}

The present clinical case reports two severe intrabony defects, compromising the tooth prognosis. One year after the periodontal regenerative therapy with enamel matrix derivative (Emdogain ${ }^{\circledR}$; Straumann ${ }^{\mathrm{TM}}$ ), it was possible to realise that teeth prognosis has changed.

According to several studies, there are significant improvements when enamel matrix derivative is used to potentiate periodontal regeneration instead of open access debridement alone or other type of biomaterials [17-21].

The regenerative approach of intrabony defects with enamel matrix derivative seems to have the same clinical result as guided tissue regeneration according to the metaanalysis conducted by Esposito and colleagues [22] idea that is compatible with the guidelines purposed by the European Federation of Periodontology for the management of intrabony defects [23].

The access flaps that are designed to preserve the interdental soft tissues are related to higher degree of success. The maintenance of the interdental space, the protection of the regenerative materials and tissues seems to be the main goals of the minimally invasive techniques [4] that have been used in this clinical case.

Antibiotic administration after enamel matrix derivative application does not seem to have any clinical relevance in pocket depth reduction and clinical attachment gain when compared to application of enamel matrix derivative without antibiotic coverage [24]. Similarly the usage of non-steroidal anti-inflammatory drugs after the reported treatment does not influence the clinical outcome, but influences the patient morbidity [25].

\section{Conclusion}

The reestablishment of periodontal apparatus should be the main goal of periodontal corrective treatment. This case demonstrates that periodontal defects with severe involvement can be successfully treated and maintained compatible with periodontal health, since a multidisciplinary treatment plan is followed. Long term outcomes will depend on the patient's compliance with the supportive periodontal programme and plaque control.

\section{References}

1. Lang NP. Focus on intrabony defects - Conservative therapy. Periodontol. 2000; 22: 51-58.

PubMed: https://pubmed.ncbi.nlm.nih.gov/11276516/

2. Papapanou PN, Wennström JL. The angular bony defect as indicator of further alveolar bone loss. J Clin Periodontol. 1991; 18: 317-322. PubMed: https://pubmed.ncbi.nlm.nih.gov/2066446/

3. Cortellini P, Stalpers G, Mollo A, Tonetti MS. Periodontal regeneration versus extraction and prosthetic replacement of teeth severely compromised by attachment loss to the apex: 5 -year results of an ongoing randomized clinical trial. J Clin Periodontol. 2011; 38: 915-924. PubMed: https://pubmed.ncbi.nlm.nih.gov/21777268/

4. Cortellini P, Tonetti MS. Clinical concepts for regenerative therapy in intrabony defects. Periodontol 2000. 2015; 68: 282-307.

PubMed: https://pubmed.ncbi.nlm.nih.gov/25867990/

5. Pretzl B, Kim TS, Holle R, Eickholz P. Long-Term Results of Guided Tissue Regeneration Therapy With Non-Resorbable and Bioabsorbable Barriers. IV. A Case Series of Infrabony Defects After 10 Years. J Periodontol. 2008; 79: 1491-1499.

PubMed: https://pubmed.ncbi.nlm.nih.gov/18673000/

6. Eickholz P, Krigar D-M, Pretzl B, Steinbrenner H, Dörfer C, Kim TS. Guided Tissue Regeneration With Bioabsorbable Barriers. II. LongTerm Results in Infrabony Defects. J Periodontol. 2004; 75: 957-965. PubMed: https://pubmed.ncbi.nlm.nih.gov/15341353/

7. PiniPrato G, Cortellini P. Thirty-year stability after regeneration of a deep intrabony defect: a case report. J Clin Periodontol. 2016; 43: 857-862. PubMed: https://pubmed.ncbi.nlm.nih.gov/27279353/

8. Nibali L, Koidou VP, Nieri M, Barbato L, Pagliaro U, et al. Regenerative surgery versus access flap for the treatment of intra-bony periodontal defects: A systematic review and meta-analysis. J Clin Periodontol. 2020; 47: 320-351.

PubMed: https://pubmed.ncbi.nIm.nih.gov/31860134/

9. Miron RJ, Sculean A, Cochran DL, Froum S, Zucchelli G, et al. Twenty years of enamel matrix derivative: the past, the present and the future. J Clin Periodontol. 2016; 43: 668-683.

PubMed: https://pubmed.ncbi.nlm.nih.gov/26987551/

10. Cortellini P, Buti J, Pini Prato G, Tonetti MS. Periodontal regeneration compared with access flap surgery in human intra-bony defects 20-year follow-up of a randomized clinical trial: tooth retention, periodontitis recurrence and costs. J Clin Periodontol. 2017; 44: 58-66. PubMed: https://pubmed.ncbi.nlm.nih.gov/27736011/

11. Sanz M, Jepsen K, Eickholz P, Jepsen S. Clinical concepts for regenerative therapyinfurcations. Periodontol2000.2015;68:308-332. PubMed: https://pubmed.ncbi.nlm.nih.gov/25867991/

12. Miller. Textbook of Periodontia. Philadelphia: Blakiston; 1950; 900.

13. Caton JG, Armitage G, Berglundh T, Chapple ILC, Jepsen S, et al. A new classification scheme for periodontal and peri-implant diseases and conditions - Introduction and key changes from the 1999 classification. J Clin Periodontol. 2018; 45: S1-8. PubMed: https://pubmed.ncbi.nlm.nih.gov/29926489/ 
14. Cortellini $P$, Tonetti MS. Minimally invasive surgical technique and enamel matrix derivative in intra-bony defects. I: Clinical outcomes and morbidity. J Clin Periodontol. 2007; 34: 1082-1088. PubMed: https://pubmed.ncbi.nlm.nih.gov/17953696/

15. Cortellini P, Prato GP, Tonetti MS. The simplified papilla preservation flap. A novel surgical approach for the management of soft tissues in regenerative procedures. Int J Periodontics Restorative Dent. 1999; 19: 589-599.

PubMed: https://pubmed.ncbi.nlm.nih.gov/10815597/

16. Lang NP, Bartold PM. Periodontal health. J Clin Periodontol. 2018; 45: S9-16.

PubMed: https://pubmed.ncbi.nlm.nih.gov/29926938/

17. Sculean A, Donos N, Chiantella GC, Windisch P, Reich E, Brecx M. GTR with Bioresorbable Membranes in the Treatment of Intrabony Defects: A Clinical and Histologic Study. Int J Periodontics Restorative Dent. 1999; 19: 501-509.

PubMed: https://pubmed.ncbi.nIm.nih.gov/10709516/

18. Cardaropoli G, Leonhardt ÅS. Enamel Matrix Proteins in the Treatment of Deep Intrabony Defects. J Periodontol. 2002; 73: 501-504. PubMed: https://pubmed.ncbi.nlm.nih.gov/12027251/

19. NCT03622255. Evaluation of Enamel Matrix Derivative as an Adjunct to Minimally Invasive Non-surgical Treatment of Intrabony Defects. 2018. https://clinicaltrials.gov/show/NCT03622255

20. Trombelli L, Bottega S, Zucchelli G. Supracrestal soft tissue preservation with enamel matrix proteins in treatment of deep intrabony defects: A report of 35 consecutively treated cases. J Clin Periodontol. 2002; 29: 433-439.

PubMed: https://pubmed.ncbi.nlm.nih.gov/12060426/

21. Trombelli L, Bottega S, Zucchelli G. Supracrestal soft tissue preservation with enamel matrix proteins in treatment of deep intrabony defects. J Clin Periodontol. 2002; 29:433-439. PubMed: https://pubmed.ncbi.nlm.nih.gov/12060426/

22. Esposito M, Grusovin MG, Papanikolaou $N$, Coulthard $P$, Worthington HV. Enamel matrix derivative $\left(\right.$ Emdogain $\left.^{\circledR}\right)$ for periodontal tissue regeneration in intrabony defects. Cochrane Database Syst Rev. 2009; 2: 247-266.

PubMed: https://pubmed.ncbi.nlm.nih.gov/20467602/

23. Sanz M, Herrera D, Kebschull M, Chapple I, Jepsen S, Beglundh T, et al. Treatment of stage I-III periodontitis-The EFP S3 level clinical practice guideline. J Clin Periodontol. 2020; 47: 4-60. PubMed: https://pubmed.ncbi.nlm.nih.gov/32383274/

24. Sculean A, Schwarz F, Becker J, Brecx M. The application of an enamel matrix protein derivative (Emdogain $\AA)$ in regenerative periodontal therapy: A review. Med Principles Practice. 2007; 16: 167-180. PubMed: https://pubmed.ncbi.nlm.nih.gov/17409750/

25. Sculean A, Berakdar M, Donos N, Auschill TM, Arweiler NB. The effect of postsurgical administration of a selective cyclo-oxygenase-2 inhibitor on the healing of intrabony defects following treatment with enamel matrix proteins. Clin Oral Investig. 2003; 7: 108-112. PubMed: https://pubmed.ncbi.nlm.nih.gov/12720115/ 